\title{
Sophia's Myth and Ways of Its Embodiment in A.I. Kuprin's Story "Olesia"
}

\author{
Guzel Mrtazovna Ibatullina \\ Candidate of Philology, Associate Professor, Federal State Budgetary Educational Establishment of Higher Professional Education, \\ "Bashkir State University" (Sterlitamak Branch) \\ Email: strbsu@mail.ru
}

\section{Doi:10.5901/mjss.2015.v6n1s2p36}

\begin{abstract}
The article is devoted to the study of the Sophia's archetype in the structure of the image of the main heroine of the story of $A$. Kuprin "Olesia". The analysis of the story reveals the mythopoetic codes, owing to which the images and motives of the Sophia's myth in its traditional Christian and epistemological variants are embodied in the narrative conceptual system of the work.
\end{abstract}

Keywords: poetry, myth, sophiology, archetype, model, symbolic context

\section{Introduction}

Sophiology, both as theological philosophical studies, and common cultural myth in modern science became the subject of the research reflection in the most different aspects (Mattews, 1992; Meyendorff, 1987; Fiene, 1989; Vallerie, 2000; Arjakovsky, 2005). Among other thing the literary studies devoted to the sophiological and epistemological tradition in the Russian classical literature become increasingly demanded and rationale. However, the existing range of works in this area is still not numerous. These problems were considered the most extendedly in the contexts of works of A. A. Blok and the literature of symbolism on the whole owing to its obviousness and the direct references to Sophiology of V.S. Solov'ev (Rychkov, 2010; Rychkov, 2011; Cioran, 1977, Panova, 2008). The substantially grounded analysis of the Russian Sophia's tradition, firstly, symbolic one was given in the monograph of N. P. Krokhina (Krokhina, 2010), but the works of A. I. Kuprin were left behind this work. Meanwhile, in our view, it is right to speak that the sophiological myth, actualized in the cultural conscious of the Silver age, plays not less role in the structure of the artistic world of Kuprin, including in the story "Olesia" analyzed below.

It will be no exaggeration to say that sophiological problems are one of the central not only for the silver age literature, but in the Russian literature of the $19-20^{\text {th }}$ century on the whole. The paradigm of the Sophia's myth in some or other extent defines the figurative conceptual coordinates of many top phenomena of literature, beginning from the era of the ancient Russian culture; it is no mere change that the first Christian cathedrals in the Russia were devoted namely to the cult of Sophia God's Wisdom (instead of Christ or God's Mother, as we could expect): as it is known, they are Sophia in Kyiv and Sophia in Novgorod; in the ancient Russian literature the Sophia's archetype in its highest form is distinctly expressed in the image of the wise maiden Fevronia ("The Story about Peter and Fevronia" (16 cent.)). Further we'll detect it in the whole range of the female images in the Russian literature of the $19^{\text {th }}$ century; this range is opened by Pushkin's Tatiana Larina and is continued by the heroines of M. Y. Lermontov, I. S. Turgenev, A. N. Ostrovskii, N. A. Nekrasov, F. M. Dostoevskii, L. N. Tolstoi, A. P. Chekhov (about Sophia's motives in the works of Dostoevskii and Leskov see, for example, in the other our works: (Ibatullina, 2004; Ibatullina, 2008). The reflexive-acknowledged culmination of Sophia's myth reaches in the works of A.A. Blok and many other authors of the turn of the century; in the literature of $20^{\text {th }}$ cent., it is detected in the structure of the female images of M. A. Bulgakov, B. L. Pasternak, M. A. Sholokhov, A. N. Tolstoi, V. P. Astaf'ev.

\section{Methods}

The works of Kuprin, as many other above-mentioned artists, at first sight are enough remote from the symbols, connected with the image of "sublime Eternal Wife"; quite often the Sophia's motives penetrated into the worlds created independently on how the author related to epistemological tradition and Sophiology of the new time. The Sophia's archetype on the whole has more ancient sources, than the study of Gnostics, as it rooted in the depth of the collective 
unconscious and archaic initial tradition that feed the mythology and folklore, as well as the creative intuition of mystics, philosophers and artists, whose "sixth sense" is related to the unusual gifts, showered on sorcerers and magicians, wizards and witches. (In these culturological contexts it is not accidentally that the heroine of the story "Olesia", "a witch" became the beloved of the hero-writer, the man with soul and talent of the artist; both heroes each in their own way show the creative energies of the World Soul, embodied by the image of Sophia God's Wisdom to the world). The study of the archetype bases of the female images in the works of Kuprin, including the Sophia's archetype, undoubtedly, represents the scientific interest and is productive for understanding of the artistic philosophy of the writer.

One of the ways of penetration of the Sophia's myth in the literary artistic consciousness of any epoch along with the Bible legends and apocryphal works was folklore (as well as its literary interpretations and overtime works of the previous epochs); the features of the Sophia's archetype are without difficulty found in the heroines of the fairy-tales of the nations of the world, including in Helens and Vasilisas the Wise in the Russian fairy-tales, the Tsar-maiden of Ershov or the Swan Princess of Pushkin. At that it should be noted that the range of fairy-tales about princess that was captivated and desired salvation (for example, "The Frog Princess") contain figurative-conceptual codes of the Sophia's myth in the epistemological variant. In "Olesia" by Kuprin the sophiological archetypes are also actualized through the associative-symbolic contexts of the national fairy-tale, first of all, here the sufficiently transparent allusions to already above-mentioned "The Frog Princess" fairy-tale are enough important.

The figure of the main heroine of the story is frankly confabulated; the folklore beginnings of the image of Olesia are pronouncedly evident so as they sometimes create the false impression at the inexperienced reader about cheap "plainness" and decorativeness. Meanwhile, it should be noted that the open references to the romanticized folklorepoetic perception of the heroine as the song-fairy beautiful and mysterious maiden are supported by less evident, coded mythopoetic "realities". Thus, only once in the story the "real" name of Olesia sounds, when she says it during the first meeting the hero: "My name is Alena... From around here - Olesia" (Kuprin, 1964). As it is known, initially Alena is the national conversational variant of the name Helen; both names are surrounded by the stable folklore aura: Alenushka and Helen the Beautiful are the popular heroines of the Russian fairy-tales, first one in a greater extent relate to the image of the fairy-tale orphan, the second one represents the invariant in the paradigm of the image of Vasilisa the Beautiful (the Wise), the Tsar-Maiden. In the heroine of Kuprin the different folklore-semantic fields are dialogically met: Olesia is both the unfortunate orphan, who lives with the grand-mother and is pursued by the evil people, and "the fantastic beauty" (expression of F.M. Dostoevskii), who is endowed by the magic gifts; she is the Frog Princess, daughter-granddaughter of old witch, who lives in the marsh, is unaccepted by the world, enchanted by the evil forces and who waits for the rescuer. Generally, the image of Olesia, as many other images, motives, plot situations of the work, is archetypically polyphonic and polysynthetic (the word also belongs to F.M. Dostoevskii) and this is principally distinction from the folklore canon, where the hero is "equal to the very himself" and one archetypical model. The archetypical components of Kuprin's images are dialogically reflected not only in each other, but in the cultural-historical, social, ethnographic and everyday and other contexts and realities of the narration, generating along with mythologization the principle of relativization and demythologization of the artistic consciousness of the work. There not merely restoration or reincarnation of the myth before us, but its artistic-admitted, reflexive-remote reproduction and image.

The externally evident folklorism of Olesia's image in reality is the reflection, the sign projection of its deep myth that defines the basic myth of the story on a whole; the Sophia's myth of the archetype can be considered sense-forming for understanding the image of the main heroine of the work and its plot; the Sophia's myth lives in the internal world of the works on the rights of the image-forming construct or internal form. It is clear that in this work we cannot give the comprehensive description and interpretation of this mythopoetic paradigm, but we'll try to define the basic images and motives, which make up the system of its artistic invariants.

The Sophia's semantics in the image of the main heroine of the story is revealed enough distinctly - the whole range of associative-symbolic, sign, allusive details, which as a rule have two-dimensional nature in the contexts of the reader's perception: from one hand, as the external attributes of the common mythologism, that surrounds Olesia, from the other hand - as the expression of the true, existential rooted personal myth of the heroine. Already the very exclusiveness, ingenuity of Olesia's image, originality of its internal or external image surround her in the sight of inhabitants by the secret aureole, not understood, and so frightening. Everyone, who meets her, can't help but notice her as the particular, "different", distinguished from the other people's nature; and certainly, this refers not to ignorance of Polesye peasants; the enlightened person, if he owns the spiritual penetration and is not isolated from the vivid reality by the own intellectual models and schemes, feels the particular spiritual personal status of the heroine. There is not merely integral and original nature of "the girl from people" before us, but in many respects the personality is really paradoxical, endowed not only with the unique qualities, but the features of contradictory, a little compatible and nevertheless harmonically existing in her and creating impression of completely female image. Olesia's in impression of the narrator is 
represented as embodiment of the ideal female personality in the ambivalent unanimity of all her parts: internal and external, spiritual and physical, sensible and intellectual, earthly and metaphysical etc.

In the system of mythopoetic codes of the European culture, that explicit the female archetypes, the similar fullness of the personal myth is typical namely for the Sophia's archetype both in its biblical hypostasis of Sophia the God's Wisdom, and in the epistemological and cabbalistic images of Sophia-Akhamot. For example, the archetypes of the Mother, Maiden, Eve, even the archetype of the God's Mother, do not display such fullness in them, expressing the separate parts and aspects of the personal ideal. Moreover, the very motif of the internal integrity at preservation of the oppositions characterizes namely the Sophia's images, which is explained by their peculiar ambivalent limited ontological nature.

Almost all basic features of the internal and external image of the heroine, including portrait ones, undoubtedly reflecting the ideal "wise beauty" and peculiar charismatic "royalty", dominant for Sophia's image are inscribed into the paradigm of Sophia's model. "My stranger (here and further separated by me), tall brunette of about twenty-twenty-five years old, behave herself lightly and harmoniously. The spacious white shirt freely and beautifully embraces her young and healthy breast. The original beauty of her face, when you once see it, it was impossible to forget it, but it was beautiful to describe it, even get accustomed to it. Its fascination lies in these big, bright, dark eyes, to which the thin brows, broken in the middle add her the elusive tint of slyness, imperiousness and naivety; in the swarthy-pink colour of skin, in the wilful curve of the lips, from which the lower one was a little fuller and stand out ahead with the decisive and capricious appearance" (Kuprin, 1964). "I thought that in all her movements there was something noble (of course, in the better sense of this enough vulgar word), some inborn graceful temperance...". Also my attention was drawn to Olesia by some aureole of mystery, superstitious reputation of the witch, whose life in the wild forest among marsh and in particular this proud certainty in all her forces, that shines in many words appealed to me" (Kuprin, 1964) In addition to already above-mentioned motives (all-sufficiency and female perfection, powerful force, exclusiveness, harmony of the spiritual and physical beginnings, the aureole of the mystery and secret), the details separated by us actualize the range of other singed moments for the Sophia's archetype, which receive the development in the further fragments of the story: ambivalent combination of naivety and imperiousness, feminity and power, innocence and experience, female vulnerability and touching courage. The aristocratic refinement of her nature and wordly-common sense and sober understanding of "the prose of life" are combined in the heroine; the childish shyness and proud independence; the spiritual depth and erotic charm; maiden gaiety, friskiness, sly playfulness and material concern in relation to everything that surround her; she is equally able to enjoy life carelessly and be the wise household in the daily life. In the accentuated way the author emphasized in the heroine the cleanness and chastity, sacrifice and dedication, delicacy and inborn tact, the feeling of sacral nature of existence and possession of the internal magic knowledge, inaccessible for others, belonging not only to the intimate secrets of the nature, but understanding the laws of existence on a whole, including the laws of the civilized society remote from her. In the paradigm the image of "clever beauty" is the clear intelligence with expressed creative-constructive energies, thirst for knowledge, talent and penetration: "...if I found difficulty to seek the expression, she herself helped me with the whole rain of the impatient issues, similar to those we offer to the stutterer, who grievously stumbled on one word. Really, at the end her versatile and lively intelligence and the fresh reflection triumphed over my pedagogical weakness. Against my will I curtained that for my environment and my upbringing (or, to say more exactly, his absence), she owned the astonishing abilities" (Kuprin, 1964).

In the cited fragment of the story, as in many others, the significant elements of the Sophia's archetype in the image of Olesia, whose unordinary beauty is combined with remarkable personal characteristics, where the dominant one is the Sophia's depth of the intuitive knowledge and understanding of the human souls, were displayed. At that the ability of all understanding as substantive feature of Sophia the Wise is particularly interpreted by the author. Emphasizing the organic nature of this ability, the naturalness and lightness, with which the intimate depth of life is revealed to the heroine, can't be the result of upbringing and education as the girl even can't read. In particular in this sense the most impressive is the speech of Olesia's character, and "the expressiveness and delicacy of the phrases in the conversation even for the ordinary girl" (Kuprin, 1964). Ivan Timofeevich thoughts: "Do you know what amaze me in you, Olesia? You grew up in the forest, having not seen anyone... However you speak so good, not worse than the real young lady. Tell me, from what source is it in you? (Kuprin, 1964). The hero also understands that all natural talents, the creative force and energy, intelligence, and thirst for the world knowledge in Olesia were fused into her womanly nature, by nothing breaking her charm, instead strengthening it, and if it is the task for him, then in the associative conceptual contexts of the work lie the typical features of the Sophia's prototype of the "clever beauty".

Especially it is necessary to emphasize the motives, typical namely for the Sophia's models of the woman ideal: the internal and external artistry and aestheticism, gaiety, friskiness, playfulness of nature are the features, not peculiar to other "ideal" female archetypes: Mother and God's Mother, Heaven Maiden, Eve, Madonna, Priestess, Queen or Witch; 
obviously, these qualities are expressed in the archetype of Aphrodite, but here many features, which are typical for the earlier named models, are not actualized. Thus, S.S. Averintsev marks that "the specificity of Sophia is composed by the female passiveness, conjugated with the mother's multifertility, her "gaiety", and the deep connection not only with the Cosmos, but with the humankind (Parable, 8.31 etc.)" (Averintsev, 1982). It should be also marked that this specific paradigmatic model really had archetypical nature, as with the surprisingly repetition was embodied in the number of female images of the Russian literature of the 19-20 th century (obviously, within the frameworks of our study we restrict ourselves by the contexts of the Russian literature, not asking the question about the Western-European or Eastern tradition). The sophiological interpretation of Kuprin's heroine undoubtedly differs from the Sophia's images of Dostoevskii, Leskov, Blok, Bunin or Pasternak, but the comparative analysis of these modifications now isn't included into our tasks.

In the context of the Sophia's paradigm of Olesia's image many details, characterizing heroine, acquire the signmetaphorical or symbolic sense. Ambivalent limited and chthonic in its essence the nature of Sophia, who owns demiurgic force of transfiguration of Chaos into Cosmos, are metaphorically reflected in the structure of chronotopes connected with the story heroine. The space of Olesia's existence is absolutely marginal and limited in relation to the rest of the world, at that the motif of the border here is repeated many times that actualizes and strengthens its literary semantic nature. Not only the dwelling of Olesia and her grandmother turns out to be on the boundary with the space of existence of people, surrounding it, who are in the state of half-wild ignorance; the very existence of the heroine marginally relative both to the world of "the big" civilization, "city", from where Ivan Timofeevich came from, and even relatively to "the big space-time history and culture", to which he, as an intelligent, enlightened person and literary man is involved. Although in spite of the marginal nature of life and consciousness of the heroine, she is showered with the feeling of belonging to the existence on a whole, that is many times revealed in the talks with Ivan Timofeevich: "She wasn't tired of asking me properly about everything that interested and excited her wild, and bright imagination: about countries and peoples, phenomena of nature, land and universe organization, erudite persons, big cities... Many things seem to be surprising, fairy and improbable" (Kuprin, 1964)

The motif of the boundary acquires metaphysical nature, as in the symbolic context of the story the life space of Olesia appears on the metaphorical boundary between Chaos and Cosmos, in the area of chthonic nature represented here by the image of the marsh and the range of figurative elements connected with it. On the one part, Olesia's existence is dipped into the world of the natural initial elements, inseparably linked with the areas of Chaos, on the other part - in the heroine the cosmourgical forces, able to arrange and harmonize Chaos, were many times designated. In this sense the sign-metaphorical character acquires many details as, for example, mention about unordinary abilities of the forest maiden; she possesses power over the elements of fire and water: "If you want, shall I treat the strongest fever in two days with the simple water (my italics), even if all your physicians refused from the sick person?" (Kuprin, 1964); similar to the solar deities, she is gifted power to subdue and control chthonic creatures: "If you want, shall I exterminate of all the mice and cockroaches from the house in one day?" [the same]; her consciousness is equally involved in the past, present and future - the different time plans of cosmically arranged existence ("...how shall I know future?"), as well as oneiric areas existing beyond the space and time ("Why do I read sleeps?" [the same]). This range of comments can be continued, but the already listed evidences about reflection of the motif of the boundary of Sophia in the structure of Kuprin's heroine image; at that it is important that restriction of life and consciousness will give her, as her sacral prototype, the opportunity to be involved almost in all everyday areas. The elements of epistemological myth about Sophia-Akhamot - captivated and suffering Sophia, "fallen" as a result of her ignorance were revealed in the ambivalent limited nature of Olesia's image. Almost literary Olesia is in the captivity of her fears and illusions, connected with her "repudiated" existence in relation to the church and imaginary connection with the devilish powers. Her "clear mind" is simultaneously wrapped into "steadfast inherited superstition" (Kuprin, 1964), that partially become the reason of future catastrophe in the destinies of heroes. The central plot collision of the epistemological myth - release and salvation of the captive Sophia - is distinctly designated in the story (including, by the figurative conceptual codes of the fairy-tale), but doesn't find its final solution; the reasons will be discussed below.

It should be noted that from the point of view of logics of Kuprin's image Olesia is not a symbol and embodiment of Sophia; the similar literary status has, probably, Nastasia Filippovna of Dostoevskii and Lara of Pasternak. The images of these heroines were frankly symbolized by the contexts of works; Kuprin's story is built, probably, according to the laws of desymbolization of the image - in the sense that the symbolic content here is stated and designated, but the image of Olesia is represented by the general literary logics of the work as the concrete implementation and individual incarnation of "endlessly generating" (expression of A.F. Losev) symbolic model of the female personal ideal. The metaphysical and irrational nature of Sophia is not the dominant of image as in the heroines of Dostoevskii, Blok or Pasternak; she was reduced by the rational psychological and scientific positivistic parts of consciousness of the hero-narrative. In this sense 
whether paradoxical it is, Kuprin can be called in some extent "more as realist" than Dostoevskii or Pasternak. Creating her "female myth", Kuprin consciously represents it not only as the metaphysical revelation, but as opportunity of those real openings in the area of the secret phenomena of the human psyche that tries to destroy the rational scientific knowledge. The narrator tells about unrecognized powers of intuition, premonition and wisdom of the millennial experience, aspiring objectively "realistically" comprehend "the magical charms" of Olesia: "The unconscious, instinctive, obscure, occasionally experience and strange knowledge, which passed ahead the exact science for the whole centuries and live, having mixed with the ridiculous and wild popular believes in the dark closed people's mass, being passed as the greatest secret from generation to generation were accessible to Olesia" (Kuprin, 1964).

\section{Results}

As it was said above the Sophia's motives were reflected in the plot of story in the history of relations of Olesia and Ivan Timofeevich. The dramatic history of love in contrast to "desymbolized" character images acquires the deep symbolic sense in the mythopoetic paradigm of work. This is conditioned firstly by that the opportunities of the rational explanation and solution of the basic conflict of the story - through "realistic" social and psychological motivations of the actions and events - doesn't give the comprehensive result, and dramatic effect of the situation and internal contradiction of the unfinished final are not taken off, but on the contrary are enhanced at the attempt to project them on the social-historic and cultural realities; as it is well-known it is in the very real, but not in the literary activity of the plot "nobleman commoner" found completely favourable outcomes. For Olesia this final turns out ti be impossible, and in the reasons of the dramatic outcomes of the events both the inevitably fatal and irrational motives (the heroine many times speaks about it) are found.

The logics of the heroine's destiny acquire the metaphysical overtones and symbol-forming character. If the personal ideal incarnated in Olesia with the very beginning of the story is represented as the phenomenal, but conceivable phenomena, as accomplished personal myth, then the history of relations of the heroes is initially projected on the life of the natural elements and is accompanied by the motives if their irrational power, unpredictability, and ambivalent nature of their energies, sometimes destructive for the human. The destructive aspect of the elemental beginnings of existence is directly designated by the narrator already in the first episodes of the story as the display of the infernal demonic powers: "Behind the walls of the house the wind raged as the old chilly and naked devil" (Kuprin, 1964). The elemental destructive energies penetrate in the areas of the human life and into the souls of people, generating the irrational elements of the superstitious aggressiveness and violent ignorance of the inhabitants. The metaphysical darkness and spiritual darkness in the figurative-conceptual contexts of the story turned out to be the intercorrelated, and the second one is perceived as the symbolic personification and expression of the first one. It is namely because of the feeling of impossibility of the individual "salvation", overcoming of the destructive forces, reigning on the earth, the feeling of the initial doom of her love appears in the soul of Olesia. At the same time the hero, who could in accordance with the epistemological plots of history of the captive and suffering Sophia and in accordance with the fairy archetype to perform the mission of the Saviour (if not the whole world, then his beloved), in reality again turns out to be not Ivan-Tsarevich, but "merely" Ivan Timofeevich in the typical role of "the unnecessary person": again there is the situation before us of "the Russian person on rendezvous" incapable in contrast to the heroine to embody in his personality the completeness of the archetypical ideal of the male character. At the same time one of the reasons of the fatal premonitions of Olesia: she with her insight sees and understands too well the weaknesses of her beloved and impossibility to make happiness with him in the world, where it is required from the man to be not only the Poet-lover, but the Knight, Warrior, Hero and Epic Hero. The personality of Olesia integrated the archetypical completeness and integrity (Maiden, Mother, Priestess, Witch, Aphrodite, Psyche, Queen etc.), the hero remains on the way to the integrity. Moreover, as opposed to Ivan Timofeevich, the heroine is able to implement in their essence not only the ideal female, but male beginning, having displayed in the extreme situation (the scene in church) of fearlessness, courage, power, dexterity and other qualities of the true Warrior: having found herself in the surrounding raged crowd, "In the attack of anger, horror and despair Olesia threw herself on her first occurred torturer so rapidly, so that she knocked her down. Immediately on the earth the scuffle boiled and the tens of bodies mixed in one general shouting mass. However Olesia as if some wonder happened, managed to slip out from this clew and she at the top speed ran along the road without the headscarf with clothes torn to rags, from which in many places her naked body was seen. After her together with foul language, laughter and hooting the stones rushed. However, only a few pursued her, but even they remained behind soon... Having run off for about fifty steps, Olesia stopped and turned her pale, scratched and blood-stained face to the brutal crown and shouted so loudly that each her word was heard on the square: "Oh, good!... You'll remember that, I promise! You'll weep to your fill yet!" This threat, as the witness of that event told me, was pronounced with such passionate hatred, decisive and prophetical tone that at one 
the new explosion of foul language was heard" (Kuprin, 1964). This episode is almost mirrored in the scene on the square, where the hero also founds himself face to face with the hostile crowd, but behaves himself directly opposite, refusing to enter into the single battle for the own honour and honour of the beloved woman: "What does it means for me, if he hears? - the peasant sprightly continued... He is only in the forest at his..." The disgusting, long and awful wordexpression hung in the air together with the violent laughter. I quickly turned my horse back and brokenly squeezed the handle of the whip, spanned by the mad rage that sees, thinks and fears nothing. Suddenly the strange, unhealthy and sad thought appeared for a moment in my head: "All that already happened many-many years ago in my life... The sun burnt hot similarly... The huge square was full with noisy and excited people. Similarly I turned back in the fit of the blind fury... However, where did it take place? When? Where?.." I drop the whip down and galloped home" (Kuprin, 1964). The reflexive intelligent (the image with the distinct allusive reference to the Hamlet archetype) forces out the potential of the real "Hero" - Knight, Warrior and Saviour in the character. This potential turns out to be unrealized, although objectively exist in his personality and consciousness; as it is not accidentally that he has the name "Ivan" traditional for the fairy hero-athlete and it is not accidentally that Olesia fell in love with him, having seen for the kindness of the weak person "the unrealized internal opportunities" (expression of V.A. Zaretskii) of the Knight with noble soul. It is not accidentally that the images finishing the story are connected with chronotopes of the window, where the hero finds the thread of "coral" beads, left by Olesia to him, and the road that remains open for the hero - similarly as for fairy Ivan Tsarevich, who went at the end of the world to look for Vasilisa the Wise lost by him (almost at the eve of the happy final) in order to obtain not only his promised wife, but the very himself. However here we pass from the sophiological plot to the initiation plot that is the theme of the individual study.

In conclusion it should be noted that really the Sophia's myth lives in "Olesia" in relation of interreflection and intercrossing with the myth of erotological, initiation myth and solar chthonic myth; this mythopoetic paradigm is displayed in the artistic structure and other works of Kuprin, for example, in 'Sulamyths" or "The Garnet Bracelet". In this range "Olesia" is remarkable by that the myth itself as the system of consciousness in its different modifications becomes here the object of the literary and philosophical reflection, and the subject of comprehension, going into relation of interreflection with the other forms of world perception, firstly, general cultural, daily and natural-scientific ones; however, the proper study of these dialogical relation stills remains beyond the frameworks of this work.

\section{References}

Arjakovsky, A. (2005) The sophiology of Father Sergius Bulgakov and contemporary Western theology. St Vladimir's Theological Quarterly, 1-2, 219-235.

Averintsev, S. S. (1982) Sophia. In Tokarev S. A. (Ed.), The Myth of the World Nations: Encyclopedia (pp. . 464-465). Moscow: Sovetskaya entsiklopedia. P. 464-465.

Cioran, S. D. (1977). Vladimir Solov'ev and the Knighthood of the Divine Sophia. Ontario: Wilfried Laurier University.

Fiene, D. M.(1989). What is the Appearance of the Divine Sophia? Slavic Review, 3, 449-476.

Ibatullina, G. M. (2004). Dostoevskii and Pasternak: the Sophia's archeoplot in the novels of "Idiot" and "Doktor Zhivago". In Trubina L. A. (Ed.), The Russian Literary of XX century. The typological aspects of studying (pp. 199-206). Moscow: Pravda.

Ibatullina, G. M. (2008). The myth - tragedy - mystery in the symbolic contexts of the story of N.S. Leskov "Perruquier". In Cherashnyaya D. I. (Ed.), Kormanov's readings: Articles and materials of Interacad. scient. conf. (pp. 108-118), Izhevsk: Udmurtia.

Krokhina, N. P.(2010). The Sophia's nature and its connotations (ontology - cosmism - eschatology) in the Russian thought in literature of XIX and the turn of XIX-XX ages. Ivanovo: GOU VPO "SHGPU".

Kuprin, A. I. (1964) Olesia. In Digest of works in 9 v. V.2 (pp. 223-292). Moscow: Pravda.

Mattews, C. (1992). Sophia Goddess of Wisdom. The Divine Feminine from Black Goddess to World Soul. London: Aquarian/Thorsons.

Meyendorff, J. (1987). Wisdom-Sophia: Contrasting Approaches to a Complex Theme. Dumbarton Oaks Papers, 41, 121-138.

Panova, L. G. (2008). The Sophia's discourse of Aleksandre Blok (on the example of "The Snow Maiden"). In Arutyunova N. D. (Ed.), The Logical analysis of the language. Between lies and fantasy (pp. 311-317). Moscow: Indrik.

Rychkov, A. L. (2010). "The Sophia's gnosis" of the Silver age: The sources and influence. In "Va, pensiero sull'ali dorate": From the history and culture of the East and West (pp. 344-363). Moscow: BGBIL.

Rychkov, A. L. (2011). The report of A. Blok about the Russian symbolism of 1910 as the development of the "thought about Sophia" of Vl. Solov'ev. Shakhmatovskii vestnik, 12, 207-231.

Vallerie, P. (2000). Modern Russian Theology: Bucharev, Soloviev, Bulgakov. Orthodox Theology in a New Key. Grand Rapids, Michigan: Dorrance Publishing. 